\title{
Hypertension Among Haitians Living in the Bahamas
}

\section{John Mazzeo \\ Department of Anthropology, Master of Public Health Program, DePaul University ${ }^{1}$}

ABSTRACT

For many Haitians in the Bahamas, migration and the process of adapting to life in an often hostile environment creates stress and may be correlated with high blood pressure. This study examines the social determinants of hypertension among Haitians in the Bahamas by exploring how experiences of migration create stress that is believed to cause high blood pressure. The Haitian explanatory model of high blood pressure, tansyon, explains the relationships between variables such as diet, stress, and poverty, and the blood. Research was conducted in several Haitian communities in New Providence and Abaco using ethnographic methods such as interviews and participant observation. Information about hypertension was also obtained during community blood pressure education workshops conducted in collaboration with Haitian community associations. This study offers valuable insights for public health efforts in the Bahamas on the issue of hypertension in the Haitian community. This study is relevant to researchers studying the connections between hypertension and migration for populations originating from less developed countries.

\section{INTRODUCTION}

Anthropological research finds that the health of migrants is adversely affected by the stress of adaptation to foreign environments and the web of barriers constructed by societies to restrict access to basic health services (Castañeda, 2010; Willen \& Castañeda, 2008; Chavez, 2003). This article investigates how the Haitian migrant experience in the Bahamas shapes the illness experience of tansyon, translated from Haitian Creole as high blood pressure, as well as the prevalence of high blood pressure in the community. This descriptive, ethnographic study involved fieldwork within Haitian migrant communities in the Bahamas from 2009 to 2010.

\section{Background}

The health challenges associated with transnational migration are among the most complicated and least studied aspects of

\footnotetext{
${ }^{1}$ John Mazzeo, Assistant Professor of Anthropology, Director of the Master of Public Health Program, DePaul University, 2343 N. Racine Ave, Chicago, Illinois, 60614

Acknowledgements: A version of this paper was presented the Society for Applied Anthropology Conference, 2011, Seattle, Washington. This research was supported by the College of Liberal Arts and Social Sciences at DePaul University. This work would not have been possible without the collaboration of several Haitian community associations. I appreciate the support from my colleagues at the College of the Bahamas. I acknowledge the fieldwork contributions of my undergraduate research assistants from DePaul University and the community health volunteers in the Bahamas. I dedicate this work in memory of Jimo and Ferdanin.
}

E-mail: jmazzeo@depaul.edu

APA reference: Mazzeo, J. (2013). Hypertension among Haitians living in the Bahamas. The International Journal of Bahamian Studies, 19, 15-30. https?/doi.org/10.15362/ijbs.v19i1.177 
globalization (Chavez, 2003). The ways in which receiving nations address the health of migrants vary. In many countries, government's inattention to health care has spurred the mobilization of community-based organizations to take primary responsibility for migrants' health needs (Nijhawan, 2005; Torres \& Sanz, 2000). The topic of migration and health has not been adequately addressed within the public health field. Moreover, there is an opportunity for cross-disciplinary research to better understand issues of health and human rights, health inequalities, and health disparities (Willen \& Castañeda, 2008; Willen, 2006). The contributions of medical anthropologists to this problem include the production of cross-cultural case studies, use of ethnographic approaches to present an "on the ground" or "insider's" perspective, and discussing why migration and health is a critical national, as well as global, concern (Castañeda, 2010; Fassin, 2004; Ho, 2003).

This research uses a theoretical approach to the cultural interpretations of illness called explanatory models. This approach was developed by medical anthropologists and examines the illness experience as "notions about an episode of sickness and its treatment that are employed by all those engaged in the clinical process" (Kleinman, 1980, p. 105). The explanatory model of an individual is "a means for understanding etiology, symptoms, pathophysiology, the course of the sickness, and its treatment" (Farmer, 1988, pp. 81-82). In the same manner, this research demonstrates how Haitians in the Bahamas use tansyon as an explanatory model that informs their understanding of the cause of their illness, associated symptoms and physiological changes, as well as the most appropriate forms of treatment.

Tansyon is presented in this article as an explanatory model that relies on cultural knowledge about the body to express how the experiences of Haitian migrants (i.e., biological, psychological and socio-economic) affect blood and cause hypertension. According to Haitian cultural models of the body, the heart mediates the balance of blood in the lower and upper extremities. Haitians attribute some illnesses, such as tansyon, to abnormal blood circulation with psychological and dietary variables having contributing roles (Laguerre, 1987). Studies of Haitians abroad, such as a study based in Miami, also find that "high blood [san wo in Haitian Creole] is blood which rises and accumulates high in the body, affecting the head and brain" (Weidman, 1979, p. 100). These studies agree that high blood is associated with heat and must be cooled and that negative feelings cause the blood to rise to the head.

This research contributes to the broader study of unauthorized migrants in the field of anthropology. This area of research has the potential to illuminate how social inequalities in the global system have tangible effects on the body as site for the inscription of policies (Castañeda, 2010). Theorizing the connections between social discrimination, structural violence, and migrant health is a way of understanding how "... history, science, racism, poverty, representation, and politics can interact synergistically to perpetuate violence by disenfranchising groups and disrupting communities and ways of life, and in the processes, [damage] the health of individuals and families" (RylkoBauer, Whiteford, \& Farmer 2009, pp. 9-10).

\section{Haitians in the Bahamas}

Haitians in the Bahamas are perceived as a social problem, called by the media The Haitian Problem, and the public generally feels they are not entitled to public health care or education despite their citizenship status (Marshall, 1979; Strachan, 2011). Population figures for the number of Haitians living in the Bahamas, Haitian migrants or HaitianBahamians, are estimated at 40,000 (13\% of 
the total population) and makes them the largest foreign ethnic group (College of the Bahamas, 2005). The Bahamas has experienced a steady flow of Haitian migrants since the 1950s and destinations have primarily been large cities such as Nassau and Freeport because of opportunities in construction work associated with the tourism industry. A smaller number of Haitians have settled on less populated islands, like Abaco, where in the past they worked on lumber and citrus farms (Marshall, 1979). Besides the opportunity for work, some Haitians view the Bahamas as a stepping-stone to the United States, as travel by boat from Haiti to the United States is both dangerous and difficult (College of the Bahamas, 2005). Most Haitians originate from the Departments of the North and Northwest and maintain strong, transnational ties as they adapt to their new environment (Marshall, 1979; College of the Bahamas, 2005).

Haitians in the Bahamas are part of a wider Caribbean diaspora fueled by poverty in Haiti and shaped by colonial and post-colonial histories in which Haitians have been exploited for their labor and controlled through violence (Zacaïr \& Reinhardt, 2010). Labor migration heightens stress and other psychosocial factors linked to increased risk of hypertension. This is especially the case for unauthorized labor migration to societies that perceive migrant groups as a social burden or problem. Epidemiological studies of populations migrating from less to more developed nations suggest that health disparities between migrants and the rest of society are the result of stress more so than changes in diet or health behaviors among migrating populations (Hedner, Kjeldsen, Narkiewicz, \& Oparil, 2010). Exposure to psychosocial stress, including routine levels of interpersonal conflict (e.g., unfair treatment or harassment), conflict, displacement, and trauma, are linked to increased rates of high blood pressure in addition to other local illness categories (Becker, Beyene, \& Pauline, 2000; Henry, 2006; James, 2010; Schoenthaler, Schwartz, Cassells, Tobin, \& Brondolo, 2010).

Throughout the region, Haitians are a stigmatized ethnic group and face marginalization by the dominant society through restrictive immigration policies, the threat of deportation, and the uncertainties of poorly paid, exploitative employment (Brodwin, 2003; Stepick, 1998). Immigration policies have been designed to promote an agenda of "Bahamianization" for creating a "Bahamas for Bahamians" by limiting and controlling Haitian migration. At the same time, the need for cheap labor by a growing economy has been satisfied through a temporary work permit system that provides Bahamian employers with the power to grant individuals the right to legally live in the Bahamas as long as they remain employed (Tinker, 2011).

Those who are born in the Bahamas (HaitianBahamians) to parents who are native-born Haitians are not granted citizenship and are essentially stateless until they apply for Bahamian citizenship at age eighteen (Frelick \& Lynch, 2005). Article 6 in the Bahamian Constitution grants citizenship to anyone in the Bahamas if both parents are citizens of the Bahamas. In 1985, an agreement was made with Haiti that provides anyone born in the Bahamas prior to 1985 with permanent citizenship regardless of their parents' citizenship status (Archer, 2005).

Perceptions of Haiti as an impoverished and diseased nation serve to rationalize immigration and citizenship policies in the Bahamas and other nations, including the United States. The myth that HIV/AIDS originated in Haiti underlies a perception and treatment of Haitians as a vector of contagion, a public health threat, and a population 
naturally prone to disease (Farmer, 1992). The perception of Haitians as illegal and as carriers of HIV is uncritically reproduced through health research from the Bahamas (Brathwaite, Brathwaite, Pratt, \& Brathwaite, 2002). The stigma of being Haitian in the Bahamas may be derived from the association of Haitians with nearly every social problem, including public health threats such as HIV/AIDS, malaria, cholera, and tuberculosis (Fielding, Ballance, Scriven, McDonald \& Johnson, 2008). These perceptions may facilitate the extraction of labor and instil a sense of fear and intimidation through violence, imprisonment, and deportation to ensure that Haitians remain silent, compliant, and hidden.

\section{Migration and Health}

The experiences of hypertension among Haitians in the Bahamas are best understood through a syndemic model that accounts for synergistic coexistence of two or more conditions, such as distress and poor diet, which creates an interactive and mutually reinforcing relationship between biological and social problems (Singer \& Clair, 2003). The interplay between biological, psychological, and socio-economic factors including marginalization, discrimination, and poverty, all contribute to the incidence of hypertension. This study affirms prior anthropological research on hypertension among Caribbean populations that highlights the complex interaction of biosocial factors (Dressler, 1982; Waldron et al., 1982). Studies that explore differences in blood pressure between proximate populations distinguished by socioeconomic status suggest that differences are the result of distress associated with the difficulties of acculturation and adaptation to changing socio-cultural environments rather than biological variables such as diet or genetics (Dressler, Grell, Gallagher, \& Viteri, 1992; Dressler, 1999; Cruickshank, et al., 2001;
Tomson \& Lip, 2005).

The Bahamas offers free health care for all who can prove residency or legal employment with a work permit (Archer, 2005). A 2005 survey of Haitians in the Bahamas found that $64 \%$ of individuals had gotten sick or had a family member fall sick since arriving in the Bahamas. Of these, $71 \%$ reported using formal health services. The most common places for care are the Princess Margaret Hospital in Nassau (46\%) and government clinics (39\%). Few (13\%) obtained services from private providers (College of the Bahamas, 2005).

In a report on health care utilization among Haitians in the Bahamas, data were collected from government clinics in New Providence, Grand Bahama and Abaco. These data show that the proportion of Haitians to Bahamians receiving antenatal, postnatal, child health, or family planning services at government clinics is relatively constant, between 26 and $30 \%$ of cases. However, the proportion of Haitians to Bahamians receiving ambulatory care, which is the category that hypertension would fall into, is far lower, only about $7 \%$ of cases (Bahamas Ministry of Health and Environment, 1994).

At the national level, hypertensive diseases rank second as the leading cause of death in the Bahamas in 2006; the first being HIV/AIDS. In 2006, deaths from hypertensive disease account for $10.1 \%$ of all deaths with a defined cause and at a rate of 51.9 per 100,000 (Bahamas Department of Statistics, 2008). Table 1 provides a crosscultural comparison of hypertension rates for the general population of the Bahamians, Haitians in rural and urban Haiti, and Haitians in the United States. All studies defined high blood pressure as systolic blood pressure >= $140 \mathrm{~mm} \mathrm{Hg}$ and/or diastolic blood pressure $>=90 \mathrm{~mm} \mathrm{Hg}$. Hypertension is a widespread and growing public health problem in the 
Bahamas generally (Bahamas Department of Statistics, 2004). The table shows that rates of hypertension in the Bahamas are lower, but similar to those in Haiti. In contrast, one study on the rates of hypertension among Haitian patients in the Miami area is exceptionally high at $88 \%$. This might be attributed to the correlation between migration and blood pressure discussed above. No studies to date have examined hypertension rates among Haitian-Bahamians.

\section{Table 1}

Cross-Study Comparison of Hypertension Rates

\begin{tabular}{l|l}
\hline Study Population & Rate \\
\hline Bahamas. General population, diagnosed $^{\mathrm{a}}$ & $21 \%$ \\
\hline $\begin{array}{l}\text { Haiti. Population based sample in urban Port- } \\
\text { au-Prince }\end{array}$ & $47 \%$ \\
\hline $\begin{array}{l}\text { Haiti. Individuals accompanying patients in } \\
\text { Port-au-Prince }\end{array}$ & $24 \%$ \\
\hline $\begin{array}{l}\text { Haiti. Patients seen at a rural clinic in Belle- } \\
\text { Anse }\end{array}$ & $27 \%$ \\
\hline Haiti. Patients seen at a rural clinic in Leone $^{\text {e }}$ & $36 \%$ \\
\hline $\begin{array}{l}\text { United States. Haitian Patients at a Miami } \\
\text { Public Hospital }\end{array}$ & $88 \%$ \\
\hline
\end{tabular}

Note. Data was drawn from the following sources: aBahamas Department of Statistics, 2005. bJean-Baptise, et al., 2006. cShipp, 2001. dLluberas, Parrish, \& Kling, 2000. eNiska \& Sloand, 2006. fPreston, Materson, Yoham, \& Anapol, 1996.

When migrants encounter racism and discrimination, there is a higher risk for hypertension (Williams \& Neighbors, 2001). Other scholars have demonstrated the historical and sociological dimensions of discrimination against Haitians and the stigma of being Haitian (Craton \& Saunders, 1998; Fielding, et al., 2008; Tinker, 2011). Harassment and abuse from immigration were detected in a 2005 survey of Haitians in the Bahamas. Thirty-seven percent reported some form of abuse from authorities and $22 \%$ have been asked to produce identification to prove they were in the country legally. In particular, individuals identified immigration police as a threat, $17 \%$ had their homes raided by immigration, 19\% had been jailed or detained by immigration, and $22 \%$ had been caught in a police raid on their community (College of the Bahamas, 2005).

Stress created by higher rates of poverty than the general population of the Bahamas may also contribute to hypertension. According to the national census, the percent of Haitians living below the poverty line in 2001 was $25 \%$, compared to Bahamians at $9 \%$ (Bahamas Department of Statistics, 2004). Income data from the Bahamas census describes Haitians as the nation's most economically disadvantaged group. The majority $(84 \%)$ of recent Haitian immigrants live below the national food basket estimate $(\$ 8,524)$. When compared to other groups from outside the Bahamas, Haitians experience higher rates of poverty: $44 \%$ of migrants from countries other than Haiti earn less than the national food basket estimate (Bahamas Department of Statistics, 2004).

Higher rates of poverty can be explained by lower wages paid to Haitians for the same types of employment. A national survey of wages in the Bahamas found differences in wages between Bahamians and nonBahamians for "elementary" occupations. In New Providence, Bahamians received a mean annual wage of $\$ 14,992$ and all nonBahamians $\$ 11,903$, a difference of $\$ 3,089$. The difference was also detected on other islands, such as Grand Bahama, where the mean annual wages for this category were $\$ 12,766$ and $\$ 11,216$ for Bahamians and nonBahamians respectively, a difference of $\$ 1,550$ (Bahamas Department of Statistics, 2007). Additionally, living conditions for Haitians are worse than those in the general population. According to the 2000 national census, $44 \%$ of Haitian households had piped water into their dwelling as compared to $90 \%$ of Bahamians. Similarly, 39\% of Haitian households used a shared toilet facility as compared to $5 \%$ of Bahamians (Fielding et al., 2008). 


\section{RESEARCH DESIGN AND METHODS}

The data presented in this article are collected from semi-structured interviews and a questionnaire administered to participants at a community-based intervention for high blood pressure. Semi-structured interviews are common in ethnographic research, are ideal for one-off interviews, and rely on prestructured questions with probes (Bernard, 2006). This approach to collecting qualitative data about health is also common in the public health field (Ulin, Robinson, \& Tolley, 2005). The community health project, suggested by community leaders, trained 32 local volunteers to collect and interpret measures of blood pressure, height and weight. In addition, the volunteers verbally delivered a short health survey in Haitian Creole. They received training in basic prevention and offered screening participants basic counseling about how to reduce blood pressure through behavior change. Masters of Nursing graduate students from DePaul University developed training strategies using materials from the American Heart Association.

Research assistants from DePaul University, with the help of Haitian Creole translators, assisted in 98 semi-structured interviews in New Providence and Abaco. ${ }^{2}$ Inclusion criteria for participants were a current resident of the Haitian village, of Haitian descent, and aged 18 to 65 years. A nonprobability sampling approach was used to select individuals for recruitment in semi-structured interviews. A convenience sample enabled researchers to capture those individuals who were interested in participating. This approach is common in ethnographic research about hard-to-access populations where no census data, community plan, or formal

\footnotetext{
${ }^{2}$ This study received approval by the DePaul University Institutional Review Board under protocol number JM101309ANT. This study also received approval in 2009 by the College of the Bahamas, Research Advisory Board.
}

sampling frame exists (Bernard, 2006). Participants were interviewed in their homes and with the assistance of a local interpreter in cases when the interviewee did not speak English fluently.

Interviews covered a range of topics including demographics, migration, livelihood activities, and health. Through open-ended discussions about tansyon, participants described their illness, its cause or etiology, their symptoms, and the treatment they used. Preliminary research about community health in the Bahamas during 2008 assisted in the development of the interview guide. Additionally, lessons learned from prior experience in collecting household-level health information in Haiti were adapted for this project. Most questions were open-ended and participants were encouraged to provide in-depth answers. Follow-up and probing questions were used to help participants provide as detailed a response as possible. Interviews lasted on average for one hour, were digitally recorded, and later transcribed.

During the process of fieldwork, local Haitian community associations expressed interest in a health education project designed specifically for Haitians that could provide basic knowledge and skills for a communitybased high blood pressure screening project. Nursing students and trained community volunteers obtained blood pressure from participants using automatic units on the upper left arm while the participant was seated. ${ }^{3}$

The community blood pressure workshops provided a rough estimate of the prevalence of high blood pressure and other health indicators in the community. Trained health volunteers conducted four workshops: three in Nassau and one in Marsh Harbour. Some of the interview participants attended the education workshops, but the majority of

\footnotetext{
${ }^{3}$ The unit used was an Omron HEM-712C.
} 
people at the workshops had not been part of the interview process.

The workshops were delivered in the evening or on the weekend, held in the community for convenience and to protect participants against the risk of being apprehended by immigration. The workshops were advertised by word of mouth and announced by religious leaders serving the community. A total of 98 people participated in this voluntary workshop. The benefits of participation included a written summary in Haitian and English of the blood pressure measurements obtained and the option to receive basic counseling by health volunteers about high blood pressure prevention. All of the health volunteers were fluent in Haitian Creole and English and had participated in the training provided by the nursing students from DePaul.

\section{Setting}

Field research was conducted on the islands of New Providence and Abaco. In New Providence, research was conducted in Haitian villages along Carmichael Road (College of the Bahamas, 2005). New Providence has the largest Haitian population in the Bahamas and Carmichael Road has many Haitian villages. This area used to be undeveloped government land dedicated to farming but is now zoned as residential and commercial. Fires destroyed two of the Haitian villages, Mackey Yard and Sou Woch, in January and March 2011, displacing residents to other neighborhoods. The government was swift to reclaim land and has plans to redevelop these sites. The island of Abaco has the second largest Haitian population in the Bahamas (College of the Bahamas, 2005). Research was conducted in two adjacent communities, the Mud and Pigeon Peas, located within the city of Marsh Harbour. Another fire in April 2011 destroyed 20 structures in the Mud, but the majority of this village remained intact.
Haitian villages are informal urban settlements that are home to both Haitian migrants and Haitian-Bahamians. HaitianBahamians are individuals of Haitian ancestry, but who are either born or raised from a very early age in the Bahamas. Some of the villages are located on government land, while others are on private property and residents are required to pay rent to the property owner. The settlements are passable by a maze of footpaths and unpaved roadways. Structures are subdivided into single rooms and are rented to individual households as living space or they are used for businesses such as convenience stores, barbershops, or take-out kitchens. Some villages have an open space used as a makeshift marketplace on the weekends; some residents have space for small gardens where they grow food, and there are trash piles and pit latrines located on the periphery. These are not official neighborhoods and because of their informal status, they do not have elected leadership. There is high variability in the kinds of services (such as piped water, electricity, and trash collection) these areas receive. The density of structures and poor construction make these villages vulnerable to disasters such as hurricanes, floods, and fires.

\section{FINDINGS}

This section examines the findings of the research beginning with a presentation of the interview findings followed by the community blood pressure education workshop findings. Interview data demonstrate how Haitians use the explanatory model of tansyon and its related metaphors of blood, heat, pressure, and distress to explain how these experiences of invisible violence manifest in their body as illness. The most common illness or reasons for seeking care in the surveyed population was high blood pressure. Of 98 people interviewed, $31 \%$ either had tansyon or lived with someone who did. The majority of participants were Haitian-born, aged 27-55 
years, and half of the participants had lived in the Bahamas for less than ten years (see Table 2).

Table 2

Interview Participant Demographics

\begin{tabular}{l|l|l|l|l}
\hline \multicolumn{2}{l|}{ Interview Participants } & $n$ & $\%$ \\
\hline $\begin{array}{l}\text { Place of } \\
\text { Residence }\end{array}$ & $\begin{array}{l}\text { New Providence } \\
\text { (Nassau) }\end{array}$ & 57 & $58 \%$ \\
\hline & \multicolumn{1}{|l}{$\begin{array}{l}\text { Abaco (Marsh } \\
\text { Harbour) }\end{array}$} & 41 & $42 \%$ \\
\hline Gender & Male & 37 & $38 \%$ \\
\hline & Female & 61 & $62 \%$ \\
\hline Place of Birth & Haiti & 79 & $81 \%$ \\
\hline & Bahamas & 6 & $6 \%$ \\
\hline Age & Missing & 13 & $13 \%$ \\
\hline $\begin{array}{l}\text { Years in the } \\
\text { Bahamas }\end{array}$ & Mean & Max & Min & SD \\
\hline Household Size & 31.0 & 80 & 20 & 13.5 \\
\hline
\end{tabular}

The findings of this research show that the internalization of violence through emotions of stress, anxiety, and fear can cause tansyon. These "hot" emotions cause blood to rise to the head. Many individuals explained their condition of tansyon as caused by daily stress stemming from economic difficulties, fear of immigration, and the responsibilities of caring for family in the Bahamas and sending remittances to those in Haiti. This research defines tansyon as a blood disease caused by stress and anxiety. The disruption causes blood to become heated and to rise to the head resulting in a similar set of symptoms across individuals and prompting a similar approach to treatment. Participants emphasized that the process by which blood becomes heated and rises is largely due to emotional stress. There was consensus among participants that when the blood rises this causes headaches, a feeling of heaviness in the head, and lethargy. Other symptoms include backaches, itching, blisters, and in serious cases, numbness, fainting, and nose bleeds.

\section{"Tansyon? Wi! [Hypertension? Yes!]"} replied Mme. Claude in Haitian Creole as she stood cooking in her outdoor kitchen during the interview. ${ }^{4}$ Tansyon in Creole is a multifaceted word that literally means tension, strain, and stress but is used to describe the experience of what is understood to be high and/or rising blood as well as the clinically diagnosed hypertensive disease. She explained,

The first time I found out I had high blood pressure was after I became dizzy and fainted. I had back pain and numbness on my side and that's when the doctor told me. (She drew a line down her side with her finger). My blood rises up and the headaches happen when I am angry or when I eat a lot of salt or fried foods. Sometimes my body starts itching and I get blisters and bumps. I mostly go to the clinic, but when I don't have enough money, I drink almond leaf tea to bring down my pressure (Mme. Claude, personal communication, December 6, 2010).

Residents of urban, informal, Haitian settlements in the Bahamas, called shantytowns by Bahamians and Haitian Villages by Haitians, constantly strategize about how to afford rent, food, find work, and avoid immigration officials. Mme. Claude relies on a combination of income streams for the purposes of offsetting the risk that any one activity might fail to generate the necessary revenue. She prepares plates of cooked food, washes clothes, and sells cold drinks out of her home. Several years ago her male partner died and it became difficult to support herself

\footnotetext{
${ }^{4}$ The names of respondents have been changed or are omitted to protect their identity.
} 
and her children. She attributes his death to cardiovascular disease and untreated high blood pressure.

She worries about her own health and how she can manage her tansyon:

When I am thinking a lot, stressed, about how I don't have enough money to take care of my kids, pay for their school. Worrying. Thinking, 'Where am I going to get this money from? How am I going to make this money?' The [blood] pressure rises. Sometimes I can't sleep. The bills pile up. Not enough money (Mme. Claude, personal communication, December 6, 2010).

When I asked how she manages her stress, she explained, "I don't have time to deal with my stress. I feel better when I go to church or when I'm cooking at night, just staying at peace, praying" (Mme. Claude, personal communication, December 6, 2010). Adding to daily economic anxieties are the immigration raids that typically occur during the night. The raids are part of a larger national campaign to arrest and deport unauthorized migrants. During raids on Haitian villages, even legal residents are reportedly subject to harassment, intimidation, threats, and requests for bribes.

Tansyon and high blood pressure are sometimes used synonymously and participants recognized that tansyon could be diagnosed by reading blood pressure and treated through prescribed medication, diet change, and exercise. However, a clinical reading of high blood pressure is a sufficient, but not necessary, indicator of tansyon. Participants recognized that emotional stress, shock or anxiety cause tansyon. Consuming hot foods, such as fried food, coffee or alcohol, are aggravating factors.

When I drink too much coffee it in my blood and it goes to my head. The coffee makes my blood rise like that (makes fast upward hand gesture from her chest toward her head). When I feel agitated or get nervous, my blood rises too. Like if you [the interviewer] and me are on bad terms, that causes my blood to rise and high blood pressure (Anonymous female, personal communication, December 8, 2010).

Chronic, high stress was the most powerful cause of tansyon according to participants. The kinds of events causing the greatest stress had to do with poverty, discrimination, and fear of deportation. Sources of stress often centered on the difficulty of finding regular employment and anxiety about not having work.

When I left Haiti I don't have no tansyon. The only reason I think this happened is because I live in stress. Sometimes I'm sitting down, chilling, and people just yell, 'Hey! Immigration is here!' I'm stressing, running, and they start beating us up (Anonymous female, personal communication, December 9, 2009).

Even those who can find work attributed stress to difficult working conditions, exploitative relationships with employers, and low wages. Some participants recognized the connections between their financial and workrelated stress with tansyon.

When we living here, we live badly. My children get sick and I even get sick living like this. But we are trying to help our family in Haiti. My family is dying in Haiti. I feel my head[ache] and I think my tansyon causes that. I am working but I don't make much money. I try to get some money saved for when I get sick and when I have problems. [Work causes me] back pains, headaches. I'm out in the sun all day. They [employers] stress me out all the time. I got plenty of problems that can cause me all kinds of sickness. Plenty 
of things cause me to stress too much, especially over here [in the Bahamas]. They don't like Haitians at all (Anonymous male, personal communication, December 14, 2010).

The threat of deportation posed by random, nighttime immigration raids or being caught on the street was another source of anxiety. In some instances, individuals reported being abused by police or immigration officers. In Nassau, immigration raids were frequent and several individuals talked about how they would sleep in the bush (uninhabited areas with thick vegetation).

Plenty of people have problems [with immigration]. When you go out shopping and the police see you they will ask you for your papers. When you say no, they arrest you and will deport you. You can't do nothing and that's a problem. When you don't have papers, you are going nowhere. Yeah, and the police come here too. When somebody sees the police, everyone goes into the bush. Six months ago I was sleeping. Twelve o'clock in the night I hear someone banging on my door saying 'It's the police open the door.' When he came in he searched everywhere. He took \$300, my cell phone, and my phone cards. There's plenty problem for Haitians in the Bahamas. Plenty problem! I don't sleep good, don't eat good, don't work good (Anonymous female, personal communication, December 7, 2009).

The nationalized health system in the Bahamas is designed to provide free care, but the reality is that access to care, especially by Haitians, is restricted by fear. The fear of deportation is present at the government-run hospital in Nassau and neighborhood clinics. Proof of identification, such as a passport or work visa, is usually requested during a visit and is interpreted as a verification of immigration status. However, no fear was reported during child wellness visits, prenatal care, or delivery. All of the discussions about fear centered on seeking care for sick adults during a health crisis.

Plenty of us are afraid to go to the hospital and afraid to go to the clinic because we don't have no paper and then when we have the sickness, we're afraid to go and we can't keep down the blood pressure, and sometimes that could kill us (Anonymous male, personal communication, December 9, 2009).

If anybody here is in good health, it's because of the grace of God. We are really mistreated. If we want to see a doctor, that is really difficult for us. You see us here looking like we are in good health. That's really not the case. We can't really receive the treatment we need because nowadays to get [medical] help you need to provide them with a work permit (Anonymous female, personal communication, December 7, 2010).

Another barrier to seeking care is the cost of filling prescriptions. Many participants talked about having had high blood pressure and taking prescribed medication for a short time because the cost of re-filling prescriptions was too expensive. People on blood pressure medication explained that they only used them when they felt symptoms, such as headaches, heart palpitations, or anxiety.

Folk remedies offer a form of treatment that allows individuals to avoid contact with health centers where they may feel threatened, is more affordable than prescription medication, and is culturally meaningful. For individuals with a prior clinical diagnosis of hypertension, $48 \%$ reported using only prescription medication, $31 \%$ only folk remedies, and $20 \%$ used both. The proportion using prescription medication for high blood pressure $(68 \%)$ is less than that of the general population of the Bahamas $(90.1 \%)$ and 
highlights the barriers to care faced by migrants (Bahamas Department of Statistics, 2004).

The week before last week I went to the hospital [Princess Margaret]. I wasn't feeling alright. I told my wife and she said, I must go because they know what's going on with my body. They gave me a prescription but I don't buy them yet 'cause I ain't got no money. I get some bush medicine and that helps me. My sister died like that. High blood pressure and sugar killed her. She keep fighting and she got better, but she didn't make it no more, and she's gone (Anonymous male, personal communication, December 8, 2009).

This population has difficulty accessing care, mostly from the high cost of medication, and some rely on folk remedies as a form of selftreatment. There are no traditional herbal specialists in any of the communities we worked. Knowledge of plant cures was learned in Haiti or provided by others who were more familiar with these types of remedies. For many of the people we interviewed, herbal home treatments were the norm, just as they are in Haiti. Almond leaf tea was the most cited folk remedy used. Studies have found that the entire almond tree is rich with ellagin, quertcetol, leucocyanidin, kaempferol, and some flavinoids known to lower blood pressure (Beauvoir, 2006).

During discussions of treatment options, participants discussed how they consume more cold foods and identified how they use almond leaf, coconut, and breadfruit as effective and available bush medicines. Prescription medication was believed to work in a similar fashion on the blood but was more potent than bush medicine in its ability to cool and settle the blood. Most participants expressed a preference for prescribed medication and explained that bush medicines were used if they could not afford to purchase medication at the pharmacy or in cases where the medication produced side effects.

\section{Community Blood Pressure Education Workshop}

Participants in the community blood pressure education workshop provided basic demographic and health information summarized in Table 3. The majority of participants were from Abaco, male, and under age 55. Although most were concerned about their blood pressure, the majority was never diagnosed or did not know their last blood pressure reading.

Table 3

Blood Pressure Education Workshop Participants

\begin{tabular}{l|l|l|l}
\hline Workshop Participants N=157 & $n$ & $\%$ \\
\hline Location & $\begin{array}{l}\text { Abaco (Marsh } \\
\text { Harbour) }\end{array}$ & 93 & $59 \%$ \\
\hline & Nassau (Nassau) & 64 & $41 \%$ \\
\hline Gender & Male & 88 & $56 \%$ \\
\hline & Female & 69 & $44 \%$ \\
\hline Age & Under 55 years & 97 & $62 \%$ \\
\hline & Over 55 years & 51 & $32 \%$ \\
\hline $\begin{array}{l}\text { High Blood } \\
\text { Concern }\end{array}$ & Missing & 9 & $6 \%$ \\
\hline & Yes, concerned & 83 & $53 \%$ \\
\hline & Not concerned & 61 & $39 \%$ \\
\hline $\begin{array}{l}\text { Prior } \\
\text { Diagnosis }\end{array}$ & Missing & 13 & $8 \%$ \\
\hline & $\begin{array}{l}\text { Unknown/Never } \\
\text { Diagnosed }\end{array}$ & 94 & $60 \%$ \\
\hline $\begin{array}{l}\text { Diagnosed with } \\
\text { High Blood } \\
\text { Pressure }\end{array}$ & 63 & $40 \%$ \\
\hline
\end{tabular}

The prevalence of blood pressure readings is provided in Table 4. Blood pressure was captured in a single reading. The workshop results show high levels of hypertension in the Haitian communities studied. Of the 157 participants 95 (61\%) had high blood 
pressure. The mean diastolic pressure was $145.7 \mathrm{mmHg}(\mathrm{SD}=23.9)$ and the mean systolic pressure was $89.3 \mathrm{mmHg}(\mathrm{SD}=$ 14.1).

\section{Table 4}

Hypertension Education Workshop Results

\begin{tabular}{l|l|l}
\hline Blood Pressure Readings & $n$ & $\%$ \\
\hline $\begin{array}{l}\text { Normal (<120 mmHg Systolic AND > } 80 \\
\text { mmHg Diastolic) }\end{array}$ & 15 & $9.6 \%$ \\
\hline $\begin{array}{l}\text { Pre-hypertension (120-139 mmHg } \\
\text { Systolic OR 80-89 mmHg Diastolic) }\end{array}$ & 42 & $26.8 \%$ \\
\hline $\begin{array}{l}\text { High Blood Pressure, Stage 1 (140-159 } \\
\text { mmHg Systolic OR 90-99 mmHg } \\
\text { Diastolic) }\end{array}$ & 50 & $31.8 \%$ \\
\hline $\begin{array}{l}\text { High Blood Pressure, Stage 2 (>160 } \\
\text { mmHg Systolic OR > 100 mmHg } \\
\text { Diastolic) }\end{array}$ & 49 & $31.2 \%$ \\
\hline No results & 1 & $0.6 \%$ \\
\hline$N=157$
\end{tabular}

Approximately one-third of participants attended the workshop because they had a prior diagnosis and were concerned about their blood pressure $(32 \%, n=51)$ and of these, a high blood pressure reading was obtained in $75 \%(n=38)$. Forty percent $(n=$ 63) of participants had neither been tested for high blood pressure nor were concerned that they might have high blood pressure. Of these individuals, $52 \%(n=33)$ received a reading indicating high blood pressure. Another group of individuals never received a blood pressure test or were unaware of their results, but were concerned about their blood pressure $(20 \%, n=32)$. Subsequently, approximately half $(53 \%, n=17)$ of these individuals received a reading indicating high blood pressure.

Obesity, a known risk factor for high blood pressure, was also measured at the education workshops. Height for weight measurements were obtained from participants and the results in Figure 1 show that more than half of all participants had a body mass index (BMI) that indicated being overweight or obese. ${ }^{5}$ The mean BMI for the population was 27.3 $(S D=4.9)$. The relationship between obesity and high blood pressure was not statistically significant. Compared to the general Bahamian population, the data show the same proportion of the sample as either underweight or normal. The data show that this sample had higher rates of being overweight, but lower rates of obesity than the Bahamian population.

\section{Figure 1}

\section{Comparison of BMI for Haitian Sample and General} Bahamian Population

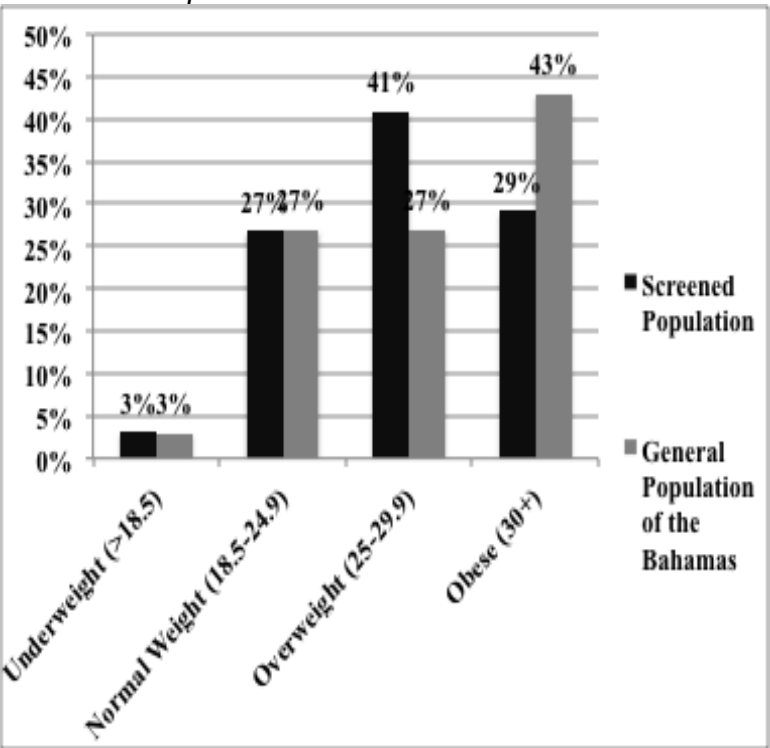

Note. Bahamas Department of Statistics (2005)

\section{DISCUSSION}

The explanatory model of tansyon among Haitians in the Bahamas relates stress and anxiety linked to daily survival in the Bahamas with hot and rising blood. Social marginalization, discrimination, and poverty are the key factors cited by participants in this study for the stress that they believe leads to tansyon. The explanatory model of tansyon is a way for Haitians to connect the difficult experience of being Haitian in the Bahamas

\footnotetext{
${ }^{5}$ Underweight was defined as a body mass index (BMI) of $<18.5$, Normal weight BMI $=18.5-24.9$, Overweight $\mathrm{BMI}=25-29.9$, Obese $\mathrm{BMI}=>=30$
} 
with an illness that has a known etiology, symptoms, and course of treatment. The barriers to care faced by many Haitians encourage the use of folk remedies commonly used in Haiti to treat tansyon. Findings from the community blood pressure education workshops suggest high levels of hypertension in the community and low number of individuals who know their status. These data highlight the value of community testing in raising awareness about blood pressure and obesity, especially for those who have not received a prior diagnosis. The active engagement with Haitian community associations demonstrates the practical relevance of this information to residents.

The high prevalence of high blood pressure in this community underscores the importance of making testing available. The slight difference in prevalence between individuals who were and who were not concerned makes the metaphor "silent killer" especially apt in this scenario and highlights the need for regular, community-wide screening. Similarly, low levels of awareness of hypertension mirror Williams' (2011) findings on the knowledge of Bahamian women with hypertension. Her work revealed high knowledge levels only among individuals who have had hypertension for more than ten years.

\section{REFERENCES}

Archer, D. (2005). The Haitian diaspora in the Abacos. [Nassau, Bahamas]: Solution.

Bahamas Department of Statistics. (2004). Bahamas living conditions survey, 2001. Nassau, Bahamas: Author.

Bahamas Department of Statistics. (2005). Basic health indicators 2006. Nassau, Bahamas: Author.

Bahamas Department of Statistics. (2007). Occupations \& wages report 2007. Nassau, Bahamas: Ministry of Finance.
Additional research on hypertension among Haitians in the Bahamas could be an effective way to mobilize community-based health initiatives and increase knowledge about hypertension within a particularly vulnerable population. One of the major limitations of this study for hypertension surveillance was that the community blood pressure education workshop captured blood pressure in a single reading. The data suggest potentially high levels of hypertension in this community, although a more clinically rigorous model of data collection for hypertension should be implemented in future public health surveillance projects. Another limitation of the study is the lack of information about the health status of participants prior to their arrival in the Bahamas. More in-depth research is required as little is known about the health status of this population prior to migrating.

\section{CONCLUSION}

This study of Haitian migrants in the Bahamas is an opportunity to understand more about the intersections of the migrant experience and health care access and outcomes (Willen \& Castañeda, 2008). It has also suggested ways that communities facing discrimination can partner with academic researchers to engage in community action research for the purposes of creating positive social change.

Bahamas Department of Statistics. (2008).

The ten leading causes of death, all ages, both sexes, all Bahamas, 2006. Nassau, Bahamas: Author.

Bahamas Ministry of Health and Environment. (1994). The impact of Haitian migration on the Bahamas: A health services digest. Nassau, Bahamas: Health Information Coordinating Services Unit.

Beauvoir, M. G. (2006). Herbs and energy: The holistic medical system of the Haitian 
people. In P. Bellgarde-Smith \& C. Michel (Eds.), Haitian vodou: Spirit, myth, and reality (pp. 112-133). Bloomington: Indiana University Press.

Becker, G., Beyene, Y., \& Pauline, K. (2000). Memory, trauma, and embodied distress: The management of disruption in the stories of Cambodians in exile. Ethos, 28(3), 320-345.

doi:10.1525/eth.2000.28.3.320

Bernard, R. H. (2006). Research methods in anthropology: Qualitative and quantitative approaches. (4th ed.). Lanham, MD:

AltaMira Press.

Brathwaite, A. F., Brathwaite, V., Pratt, C., \& Brathwaite, N. (2002). HIV infections in Grand Bahama, 1991-1995: A comparative analysis with 1985-1990. Bahamas Journal of Science, 10(1), 23-29.

Brathwaite, N., Brathwaite, A., \& Taylor, M. (2011). The socio-economic determinants of obesity in adults in the Bahamas. West Indian Medical Journal, 60(4), 434-441.

Brodwin, P. (2003). Marginality and subjectivity in the Haitian diaspora. Anthropological Quarterly, 76(3), 383410. doi:10.1353/anq.2003.0034

Castañeda, H. (2010). Im/migration and health: Conceptual, methodological, and theoretical propositions for applied anthropology. NAPA Bulletin, 34, 6-27. doi:10.1111/j.1556-4797.2010.01049.x

Chavez, L. R. (2003). Immigration and medical anthropology. In N. Foner (Ed.), American arrivals: Anthropology engages the new immigration (pp. 197-228). Santa Fe, NM: School of American Research Press.

College of the Bahamas. (2006). Haitian migrants in the Bahamas, 2005: A report for the International Organization for Migration. Nassau, Bahamas: International
Organization for Migration. Retrieved from

http://iom.int/jahia/webdav/site/myjahiasite /shared/shared/mainsite/published_docs/bo oks/Haitian_Migrants_Report.pdf

Craton, M., \& Saunders, G. (2000). Islanders in the stream: A history of the Bahamian people. Vol. 2. Athens: University of Georgia Press.

Cruickshank, J. K., Mbanya, J. C., Wilks, R., Balkau, B., McFarlane-Anerson, N., \& Forrester, T. (2001). Sick genes, sick individuals or sick populations with chronic disease? The emergence of diabetes and high blood pressure in African-origin populations. International Journal of Epidemiology, 30, 111-117. doi:10.1093/ije/30.1.111

Dressler, W. W. (1982). Hypertension and culture change: Acculturation and disease in the West Indies. South Salem, NY: Redgrave.

Dressler, W. W. (1999). Modernization, stress, and blood pressure: New directions in research. Human Biology, 71(4), 583605.

Dressler, W. W., Grell, G. A., Gallagher, P. N., \& Viteri, F. E. (1992). Social factors mediating social class differences in blood pressure in a Jamaican community. Social Science \& Medicine, 35(10), 1233-1244. doi:10.1016/0277-9536(92)90177-R

Farmer, P. (1988). Bad blood, spoiled milk: Bodily fluids as moral barometers in rural Haiti. American Ethnologist, 15(1), 62-83. doi:10.1525/ae.1988.15.1.02a00050

Farmer, P. (1992). AIDS and accusation: Haiti and the geography of blame. Berkeley: University of California Press.

Fassin, D. (2004). Social illegitimacy as a foundation of health inequality: How the political treatment of immigrants 
illuminates a French paradox. In A. Castro \& M. Singer (Eds.), Unhealthy health policy: A critical anthropological examination (pp. 203-214). Walnut Creek, CA: Altamira Press.

Fielding, W. J., Ballance, V., Scriven, C., McDonald, T., \& Johnson, P. (2008). The stigma of being "Haitian" in the Bahamas. The College of the Bahamas Research Journal, 14, 38-50. Retrieved from http://journals.sfu.ca/cob/index.php/files/ar ticle/view/97/110

Frelick, B., \& Lynch, M. (2005).

Statelessness: A forgotten human rights crisis. Forced Migration Review, 24, 6566. Retrieved from http://www.fmreview .org/FMRpdfs/FMR24/FMR2439.pdf

Hedner, T., Kjeldsen, S., Narkiewicz, K., \& Oparil, S. (2010). Blood pressure and migration. Blood Pressure, 19(2), 65-66. doi:10.3109/08037051003731724.

Henry, D. (2006). Violence and the body: Somatic expressions of trauma and vulnerability during war. Medical Anthropology Quarterly, 20(3), 379-398. doi:10.1525/maq.2006.20.3.379

Ho, M. J. (2003). Migratory journeys and tuberculosis risk. Medical Anthropology Quarterly, 17(4), 442- 458. doi:10.1525/maq.2003.17.4.442

James, E. C. (2010). Democratic insecurities: Violence, trauma, and intervention in Haiti. Berkeley: University of California Press.

Jean-Baptise, E. D., Larco, P., Charles-Larco, N., Vilgrain, C., Simon, D., \& Charles, R. (2006). Glucose intolerance and other cardiovascular risk factors in Haiti (PREDIAH). Diabetes \& Metabolism, 32(5), 443-451. doi:10.1016/S12623636(07)70302-6

Kleinman, A. (1980). Patients and healers in the context of culture: An exploration of the borderland between anthropology, medicine, and psychiatry. Berkeley: University of California Press.

Laguerre, M. S. (1987). Afro-Caribbean folk medicine. South Hadley, MA: Bergin and Garvey.

Lluberas, G., Parrish, L. A. M., \& Kling, C. M. (2000). Hypertension prevalence in a rural Haitian missionary clinic. The Nurse Practitioner, 25(11), 59-61. doi:10.1097/00006205-200025110-00005

Marshall, D. (1979). The Haitian problem: Illegal migration to the Bahamas. Kingston, Jamaica: Institute of Social and Economic Research, University of the West Indies.

Nijhawan, M. (2005). Deportability, medicine, and the law. Anthropology \& Medicine, 12(3), 271-285. doi:10.1080/13648470500291436

Niska, R. W., \& Sloand, E. (2010). Ambulatory medical care in rural Haiti. Journal of Health Care for the Poor and Underserved, 21(1), 70-80. doi:10.1353/hpu.0.0256.

Preston, R. A., Materson, B. J., Yoham, M. A., \& Anapol, H. (1996). Hypertension in Haitians: A pilot survey of a public teaching hospital multispecialty clinic. Journal of Human Hypertension, 10(11), 743-745. doi:10.1016/08957061(95)97872-O

Rylko-Bauer, B., Whiteford, L. M., \& Farmer, P. (2009). Prologue: Coming to terms with global violence and health. In B. RylkoBauer, L. M. Whiteford, \& P. Farmer (Eds.), Global health in times of violence (pp. 3-16). Santa Fe, NM: School for Advanced Research Press.

Schoenthaler, A. M., Schwartz, J., Cassells, A., Tobin, J. N., \& Brondolo, E. (2010). 
Daily interpersonal conflict predicts masked hypertension in an urban sample. American Journal of Hypertension, 23(10), 1082-1088. doi: 10.1038/ajh.2010.141

Shipp, M. L. (2001). Awareness status and prevalence of hypertension in a group of urban Haitians: Findings of a populationbased survey. Ethnicity \& Disease, 11(3), 419-430.

Singer, M., \& Clair. S. (2003). Syndemics and public health: Reconceptualizing disease in bio-social context. Medical Anthropology Quarterly, 17(4), 423-441. doi:10.1525/maq.2003.17.4.423

Stepick, A. (1998). Pride against prejudice: Haitians in the United States. Boston, MA: Allyn and Bacon.

Strachan, I. G. (2011, June 2). The Haitian problem. Nassau Guardian. Retrieved from http://www.thenassauguardian.com /index.php?option=com_content $\&$ view $=$ art icle $\&$ id $=10752 \&$ Itemid $=86$

Tinker, K. L. (2011). The migration of peoples from the Caribbean to the Bahamas. Gainesville: University Press of Florida.

Tomson, J., \& Lip, G. Y. (2005). Blood pressure demographics: Nature or nurture, genes or environment? BMC Medicine, 3(3). doi:10.1186/1741-7015-3-3

Torres, A. M., \& Sanz, B. (2000). Health care provision for illegal immigrants: Should public health be concerned? Journal of Epidemiology and Community Health, 54, 478-479. doi:10.1136/jech.54.6.478

Ulin, P. R., Robinson, E. T., \& Tolley, E. E. (2005). Qualitative methods in public health: A field guide for applied research. San Francisco, CA: Jossey-Bass.

Waldron, I., Nowotarski, M., Freimer, M., Henry, J. P., Post, N., \& Witten, C. (1982). Cross-cultural variation in blood pressure:
A quantitative analysis of the relationships of blood pressure to cultural characteristics, salt consumption and body weight. Social Science \& Medicine, 16(4), 419-430. doi:10.1016/02779536(82)90050-8

Weidman, H. H. (1979). Falling-out: A diagnostic and treatment problem viewed from a transcultural perspective. Social Science and Medicine, 13B(2), 95-112. doi:10.1016/0160-7987(79)90003-6

Willen, S. (2006). "Illegal" migration as a new global health challenge: Israeli perspectives and European comparisons. (Unpublished master's thesis). Emory University. Atlanta, GA.

Willen, S., \& Casteñeda, H. (2008, November). Society for Medical Anthropology "Take a stand" initiative on "Unauthorized im/migration and health". Paper presented at the Annual Meeting of the Critical Anthropology of Global Health (CAGH) Interest Group at the American Anthropological Association Annual Meeting, San Francisco. Retrieved from http://www.medanthro.net/stand/immigrati on/SMA_CAGH_ImmigrationAndHealth0 6.2009.pdf

Williams, D. R., \& Neighbors, H. (2001). Racism, discrimination and hypertension: Evidence and needed research. Ethnicity and Disease, 11(4), 800-816.

Williams, E. J. (2011). The influence of knowledge and self-efficacy on Bahamian women's adherence to a hypertensive medication regime. (Unpublished doctoral dissertation). Barry University, North Miami, FL.

Zacaïr, P., \& Reinhardt, C. (2010). Introduction. In P. Zacaïr (Ed.), Haiti and the Haitian diaspora in the wider Caribbean (pp. 1-10). Gainesville: University Press of Florida. 